\title{
Polymers Made by Inverse Vulcanization for Use as Mercury Sorbents
}

\author{
Justin M. Chalker*a \\ Maximilian Mann ${ }^{a}$ \\ Max J. H. Worthington ${ }^{a}$ \\ Louisa J. Esdaile*a,b \\ ${ }^{a}$ Flinders University, Institute for Nanoscale Science and Technology, Sturt Road, \\ Bedford Park, South Australia, 5035, Australia

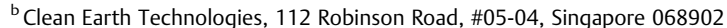 \\ justin.chalker@flinders.edu.au; louisa.esdaile@cleanearth.tech
}

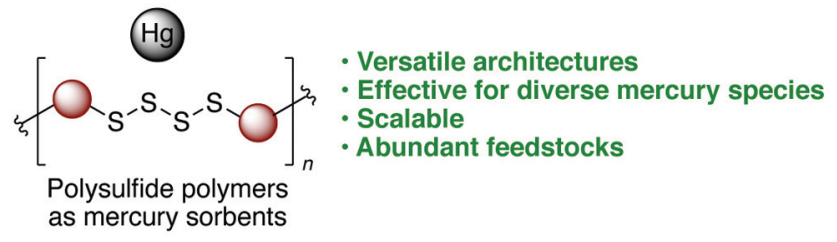

compounds, and mercury metal. ${ }^{3}$ These different forms of mercury influence its mobility in the environment, necessitating sorbents that can remove mercury from solid mixtures, fluids, and gases., ${ }^{5,6}$

Mercury sorbents must be cost-effective for uptake in industry. For this reason, relatively low-cost materials such as activated carbon have been widely used. ${ }^{7}$ Nevertheless, there remains a need to develop complementary or superior mercury sorbents to address the many challenges encountered in mercury remediation and emission control. For instance, it is useful if the sorbent is effective against the different forms of mercury. ${ }^{5}$ The rate and capacity of mercury sorption should also be high for general use, without any leaching of bound mercury. ${ }^{5}$

Sulfur has long been known to form strong bonds with heavy metals such as mercury. ${ }^{6}$ Accordingly, extensive research has been carried out to develop mercury sorbents functionalized with sulfur. ${ }^{8}$ Recently, polymers made from elemental sulfur have garnered much attention as mercury sorbents. ${ }^{9-12}$ These polymeric mercury sorbents are especially interesting because they are made directly from lowcost and highly abundant elemental sulfur. ${ }^{13}$ In this review, we focus on mercury sorbents made by the process of inverse vulcanization-a bulk copolymerization of elemental sulfur and an unsaturated organic crosslinker. ${ }^{14}$ We first provide a brief overview of this reaction and then highlight some features that make the materials intriguing and useful candidates as mercury sorbents. Our focus will be placed on polysulfide polymers (macromolecules containing S-S bonds in the polymer backbone), so other mercury-binding polymers made from sulfur that do not contain polysulfides will not be discussed in this review. ${ }^{15,16}$ Likewise, this review is not intended to be a comprehensive account of mercury remediation or inverse vulcanization, but rather a focused discussion on the unique ways in which polysulfides made by inverse vulcanization can be made and used in versatile ways to trap mercury. To this end, we discuss methods to make these materials higher in surface area, crosslinker effects in mercury sorption, the effect of mercury speciation, and life-cycle management of the sorbents. 
Biosketches

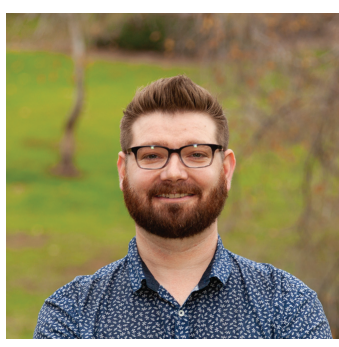

Dr. Justin Chalker was trained in organic synthesis at the University of Pittsburgh before completing his D. Phil. in Organic Chemistry at the University of Oxford in 2011 as a Rhodes Scholar and National Science Foundation Graduate Research Fellow.

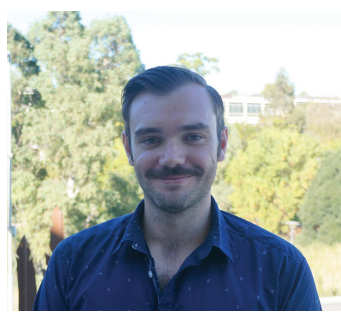

Maximilian Mann is a Ph.D. candidate at Flinders University working under the supervision of Associate Professor Justin Chalker. Max's research focuses on the synthesis and

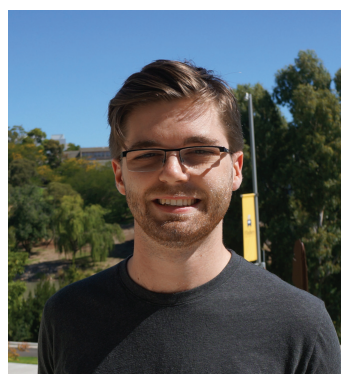

Dr. Max Worthington completed his Ph.D. at Flinders University in 2020, working under the supervision of Associate Professor Justin Chalker. Max has published a number of studies

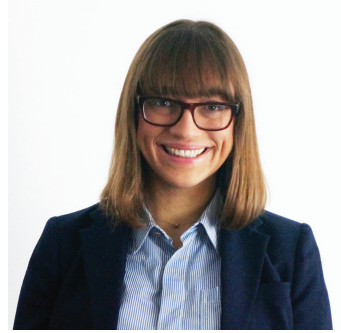

Dr. Louisa Esdaile completed her Ph. D. at Queensland University of Technology (QUT) in 2007 before moving to post-doctoral research positions with Prof. Harry Anderson at the University of Oxford in 2007 and then with Prof. Sir J. Fraser Stoddart
Justin then started his independent career at The University of Tulsa in 2012 and in 2015 he moved to Flinders University in Adelaide, Australia where he is currently an Associate Professor in the Institute for Nanoscale Science and Technology. Justin's research interests include sustainable materials and green chemistry, with a focus on translating these interests to commercial products and processes. In 2020 , Justin was awarded the Prime Minister's Prize for New Innovators-one of the top science prizes in Australia. applications of polymers made from sulfur. This research spans precision fertilizers, mercury sorbents, and novel methods for gold extraction and recovery from ore and electronic waste. Max is also studying various mechanistic aspects and design principles for controlling the properties of polymers made by inverse vulcanization. on innovative applications of sulfur polymers including their use as mercury sorbents and materials for oil spill clean-up. Max is currently a Research Associate, working at Flin- ders University in collaboration with Clean Earth Technologies on multiple commercial products that involve sulfur polymers.

\section{Sulfur Polymers by Inverse Vulcanization}

While the polymerization of sulfur has a long history in both industry and the chemical sciences, ${ }^{17-19}$ renewed interest in this area was prompted by the publication of a landmark study by Pyun and collaborators in Nature Chemistry in 2013. ${ }^{14}$ In this report, the authors introduced "inverse vulcanization" as a process to prepare polymeric materials with high sulfur content (typically $>50 \%$ by mass). Conceptually, classic vulcanization is the process by which at Northwestern University in 2009. In these roles Louisa investigated porphyrin chemistry, molecular electronics, and self-assembly. Louisa then took an industrial position with Dow Electronic Materials before returning to Australia in 2015. Currently, Dr.
Esdaile is a Project Manager with Clean Earth Technologies, with a joint academic appointment at Flinders University. Louisa directs commercial projects on mercury remediation, sustainable materials, and electronic waste recycling. elemental sulfur is used to cross-link organic polymers such as natural rubber, while inverse vulcanization is the process by which organic molecules are used to cross-link sulfur polymers. ${ }^{14}$ In this way, inverse vulcanization provides polysulfide-rich materials that are distinct from other classes of carbon-based polymers in their chemical reactivity and their physical and optical properties (Figure 1). ${ }^{20-23}$

The mechanism of the inverse vulcanization reaction has not been fully elucidated and it may vary depending on the reaction conditions, the organic crosslinker, ${ }^{24-26}$ or the use 


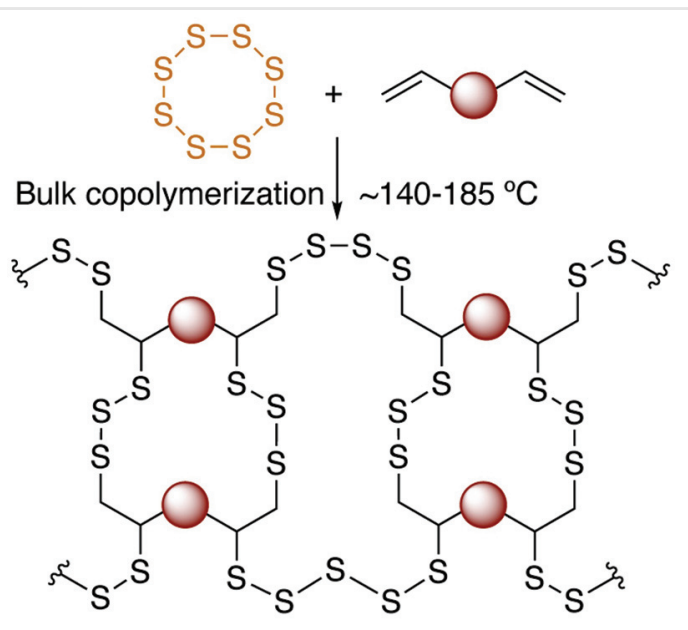

Figure 1 The copolymerization of elemental sulfur and an organic crosslinker such as a polyene can provide polysulfide polymers with high sulfur content, in some cases with $>50 \%$ of the mass derived from sulfur. The polysulfide structure imparts unique reactivity, physical, and optical properties to these polymers, including in their affinity for mercury.

of a catalyst or accelerator. ${ }^{27}$ Nevertheless, one mechanism by which the process might occur is as follows: first, elemental sulfur is melted and heated to a sufficiently high temperature to provoke ring-opening polymerization via a radical mechanism. ${ }^{17}$ The resulting linear polymer of sulfur contains thiyl radicals, which can add to the pi bond of the organic crosslinker. ${ }^{28}$ Most commonly, the organic crosslinker is a molecule containing two or more alkenes, though monoalkenes such as styrene and crosslinkers with alkyne groups have also been used in this reaction. ${ }^{20-23}$ The resulting intermediate formed after the thiyl-ene reaction can then react with another sulfur group (for instance the $\mathrm{S}-\mathrm{S}$ bond of another sulfur polymer), forming a second C-S bond. Termination could potentially occur through radical recombination. ${ }^{14}$

Evidence for a radical mechanism is a detectable electron paramagnetic resonance signal in the ring-opening polymerization of sulfur ${ }^{17}$ and in the product copolymer before termination. ${ }^{28}$ The reaction of sulfur with the pi bond of the alkene (or alkyne) has been inferred from NMR spectroscopy. 9,14 The consumption of elemental sulfur in the reaction is consistent with both X-ray diffraction (XRD) and differential scanning calorimetry analyses of the final polymer. ${ }^{12}$ The presence of S-S bonds of the polysulfides in the final product has been inferred through chemical reactivity with reducing agents and nucleophiles, $9,14,29$ mass spectrometry, ${ }^{30}$ and Raman spectroscopy. ${ }^{9,10}$ Divergence in the mechanism described above can occur, for instance, when $\mathrm{C}-\mathrm{H}$ abstraction of the crosslinker results in branching, ${ }^{24}$ when the organic crosslinker undergoes homopolymerization, ${ }^{25}$ or when nucleophilic additives or comonomers activate sulfur. ${ }^{27,31}$ The mechanism and resulting polymer can also change on the specific protocol used in the polymerization. ${ }^{26}$ For instance, the sulfur can be added at the same time to the reaction vessel as the crosslinker, or the sulfur pre-polymer can be formed before the addition of the organic crosslinker. ${ }^{26}$ Curing the polymer also may result in different crosslinking density and material properties of the final polymer. ${ }^{26}$

Materials made by inverse vulcanization can also vary widely in their physical properties, which are determined by the amount of sulfur in the polymer, the average length of the polysulfide chains (the sulfur rank), and the structure of the organic crosslinker. ${ }^{26,32}$ Low-molecular-weight waxes, soft and hard rubber, and brittle glasses are all accessible with this chemistry. ${ }^{32}$ Glass transition temperatures for these materials can vary from -20 to $130{ }^{\circ} \mathrm{C} .^{32,33}$ Some degree of control can be exerted by varying these parameters, but general design principles for this class of materials remains an outstanding challenge for the field. ${ }^{30,32}$ Nevertheless, the unique chemical and physical properties of these polymers have encouraged increasing evaluation in a variety of applications such as energy storage, ${ }^{14}$ infrared optics, ${ }^{34-36}$ repairable materials, ${ }^{29,37,38}$ metal binding, ${ }^{9,27,39}$ oil spill cleanup, ${ }^{40}$ composite synthesis, ${ }^{41-44}$ slow-release fertilisers, ${ }^{45,46}$ adhesives, ${ }^{29,47}$ functional coatings, ${ }^{27,30}$ thermal insulation, ${ }^{44,48,49}$ shapememory materials, ${ }^{50}$ precursors to activated carbon, ${ }^{51}$ and antimicrobial agents. ${ }^{52,53}$ No doubt the functional versatility of these materials will lead to even more applications in the future. ${ }^{21,23}$

Another important use for polymers made by inverse vulcanization is in mercury sorption, an application first reported by our lab in 2015.9,54 The high sulfur content and polysulfide structure impart unique mercury-binding capabilities to these materials, which has prompted a flurry of research and industrial activity in this space, as discussed in the next sections.

\section{Sulfur Polymers as Mercury Sorbents}

In our study on the copolymerization of limonene and sulfur, we found that the product forms short oligomers rather than high-molecular-weight materials. ${ }^{9}$ This phenomenon was attributed to chain termination (perhaps through $\mathrm{C}-\mathrm{H}$ abstraction) with concomitant oxidative aromatization of limonene to $p$-cymene. ${ }^{9}$ The formation of the low-molecular-weight product was fortuitous because the polymer could therefore be used directly as a coating and it could be solvent-processed. ${ }^{9}$ Hasell and coworkers later took advantage of the solubility of the limonene polysulfide as a coating for silica, observing excellent mercury-binding performance $\left(>700 \mathrm{mg} \mathrm{Hg}^{2+} / \mathrm{g}\right.$ polymer absorbed from a $400 \mathrm{ppm}$ solution of $\mathrm{HgCl}_{2}$ in 1 hour). ${ }^{27}$ In the original limonene study, it was also 
revealed that the polysulfides behave as reactive sorbents, undergoing chemosorption with $\mathrm{Hg}^{2+}$ and converting it to a mercury sulfide species. ${ }^{9}$ In the case of $\mathrm{HgCl}_{2}$ this reaction with the limonene polysulfide produced a chromogenic response, converting the dark red material to a bright yellow product (Figure 2). The chromogenic response was selective for mercury and no color change was observed for any of the other metal salts tested. ${ }^{9}$ This finding therefore opened the possibility for not just mercury remediation, but also mercury sensors and self-indicating sorbents. ${ }^{9}$ In Figure 2, the limonene polysulfide was evaluated as a simple twodimensional surface. Increasing the surface area of the polymer support or the polymer itself is an important strategy for improving the rate and capacity of the polymer as noted previously. Next, we discuss other strategies for increasing the surface area of sulfur polymers for use as mercury sorbents.

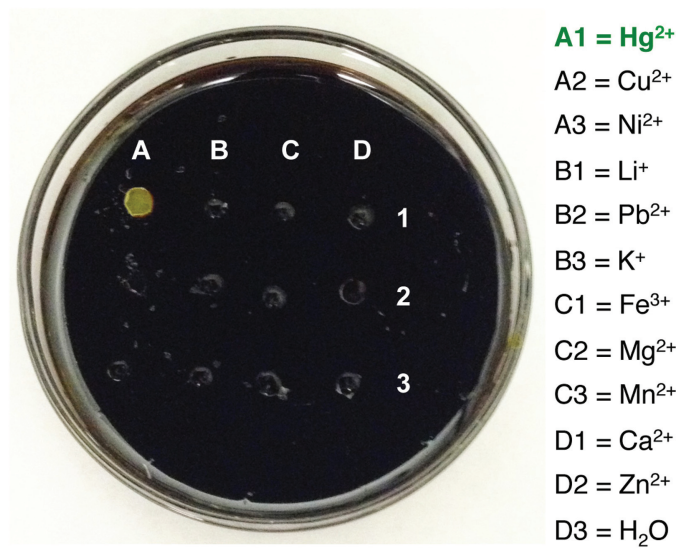

Figure 2 The copolymerization of limonene and sulfur provides lowmolecular-weight materials that can be solvent-processed and used as a coating. In the image, the limonene polysulfide surface was treated with a variety of metal solutions. The yellow material is the product of the reaction of the limonene polysulfide with the mercury salt. ${ }^{9}$ Reprinted with permission from the authors. Copyright 2016 Justin Chalker.

\section{Increasing Surface Area to Improve Mercury Uptake}

A number of strategies have been reported for obtaining high surface-area polymers made by inverse vulcanization. Foaming with an inert gas, for example, was first reported by Hasell and collaborators to improve mercury sorption capacity. ${ }^{11}$ In this study, supercritical carbon dioxide $\left(\mathrm{scCO}_{2}\right)$ was used to foam a polymer made from sulfur and 1,3-diisopropenyl benzene (DIB) (the original polymer reported by Pyun and associates in the development of inverse vulcanization). ${ }^{14}$ Hasell et al. found that the $\mathrm{scCO}_{2}$ could permeate and swell the polymer at $80^{\circ} \mathrm{C}$ and $28 \mathrm{MPa}$ in an autoclave. Upon release of the pressure, the polymer readily foamed and formed a porous structure. The microporous polymer captured an order of magnitude more $\mathrm{HgCl}_{2}$ in comparison to the unfoamed polymer, illustrating the importance of high surface area. ${ }^{11}$

Liu and co-workers reported a complementary strategy for foaming in which the $\mathrm{CO}_{2}$ is generated by the thermolysis of their polymer. The $\mathrm{CO}_{2}$ is generated by the decarboxylation of a Meldrum's acid side chain of the polymer. ${ }^{55}$ The self-foaming material had a mercury sorption capacity of $52 \mathrm{mg} \mathrm{Hg}^{2+} / \mathrm{g}$ polymer. When a $100 \mathrm{mg}$ sample of the polymer was added to a $10 \mathrm{~mL}$ solution of $\mathrm{HgCl}_{2}$ (2240 ppb), 95\% of the mercury was removed after 3 hours. ${ }^{55}$

Porosity can also be imparted to the sulfur polymers using a porogen. In this strategy, the polymerization or polymer curing is done in the presence of an inert, water soluble material (such as sodium chloride crystals) which can be washed from the polymer after polymerization is complete. The void spaces resulting in the polymer after washing impart surface area that increases mercury sorption performance. Hasell and co-workers developed a salt-templating process for generating porosity. ${ }^{12,56}$ In this strategy, sodium chloride was precipitated from water to form micron-scale crystals, fused together as a template (Figure 3a). A liquid pre-polymer (formed from the partial reaction of sulfur with dicyclopentadiene, for instance) was then poured into a mold containing the salt template. After curing at $135{ }^{\circ} \mathrm{C}$ for 24 hours, the salt was removed in boiling water. Mercury saturation capacities on the order of $2 \mathrm{mg} \mathrm{Hg}^{2+} / \mathrm{g}$ polymer were reported for these materials. ${ }^{56}$ And while these capacities are relatively modest, it should be noted that this is a relatively simple way to impart surface area to these materials.

Similar strategies for using sodium chloride as a porogen were reported by Alhassan ${ }^{48,57}$ and co-workers and our laboratory. ${ }^{10,40}$ In both cases, the sodium chloride porogen (up to $70 \%$ of the mass of the reaction mixture) was added directly during the polymer synthesis. The polymer vitrified around the surface of the salt, and then the product was ground and washed with water to remove the porogen. Preparing a polymer from sulfur and DIB with this method, Alhassan and collaborators demonstrated both elemental mercury vapor uptake $(151 \mu \mathrm{g} / \mathrm{g})^{48}$ and inorganic mercury ion uptake from water $(371 \mu \mathrm{g} / \mathrm{g}) .{ }^{57}$ Using this salt porogen method, our lab has demonstrated that the resulting polymer foam can bind diverse forms of mercury including mercury metal, mercury gas, alkyl mercury compounds, inorganic mercury, and inorganic mercury bound to humic matter. ${ }^{10}$ We have also found that for large-scale batch bulk polymerizations of sulfur and unsaturated triglycerides (on the order of $1 \mathrm{~kg}$ polymer), the sodium chloride also serves as a diluent that can help to partially control the exothermic reaction. 40 


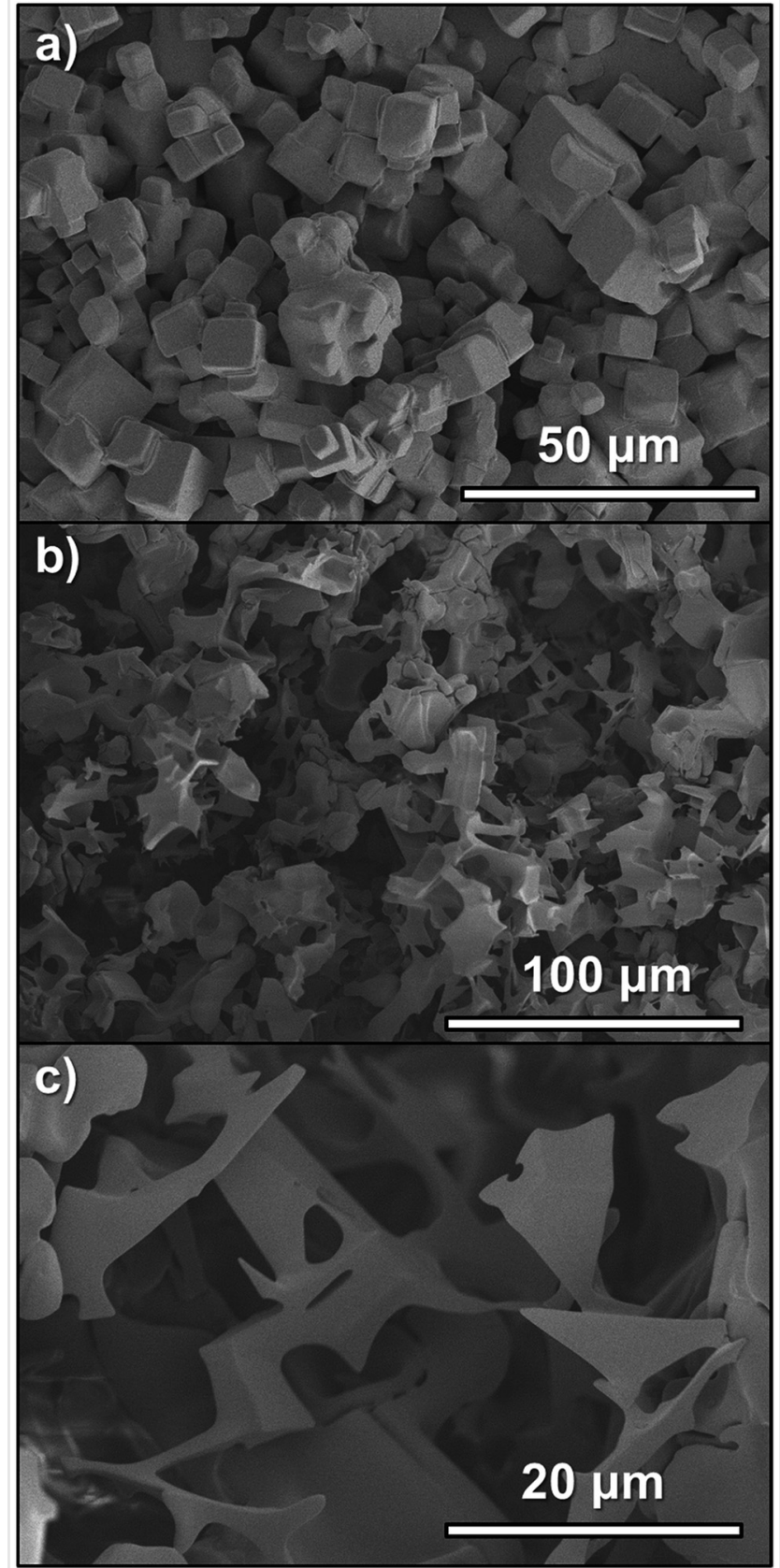

Figure 3 a) Salt template with fused sodium chloride porogen crystals. b) and c) Porous copolymer formed from the sulfur and dicyclopentadiene ( $50 \mathrm{wt} \%$ sulfur) after curing on the salt template and then removing the sodium chloride in water. Reprinted with permission from Ref. 12. Copyright 2017 Royal Society of Chemistry.

Electrospinning has long been used as a versatile method to make high surface-area micro- and nanofibers from polymers. ${ }^{58,59}$ This technique has also been extended to polymers made from inverse vulcanization, for applications in mercury remediation. For instance, Theato and collaborators first reported that commercially available poly (methyl methacrylate) (PMMA; $M_{\mathrm{w}}=109,000 \mathrm{~g} / \mathrm{mol}$ ) could be blended with poly(S-r-DIB) (50 wt\% sulfur) in a ratio of $1: 2$ by mass in a solution of THF and DMF. ${ }^{60}$ The PMMA carrier polymer was important for preventing beading on the fiber and also improving mechanical strength. The fibers produced under the optimized conditions were an average $970 \mathrm{~nm}$ in diameter (Figure 4).

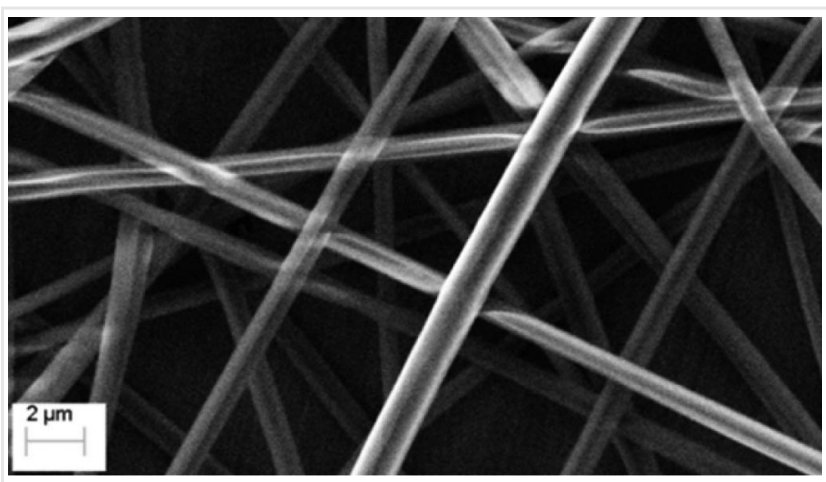

Figure 4 Electrospinning a solution of 15 wt\% poly-(S-r-DIB) and 7.5 wt\% poly(methyl methacrylate) produces high-surface-area fibers. The fibers bound $440 \mathrm{mg}$ of $\mathrm{Hg}^{2+}$ per gram of fiber, removing the heavy metal from water in seconds. Reprinted from Ref. 60 published under a creative commons license (CC BY).

The high surface area of the sulfur-rich fibers imparted high rates of mercury uptake. For instance, in only a few seconds, $98 \%$ of $\mathrm{Hg}$ (II) was removed from water containing $20 \mathrm{ppm}$ of mercury. Interestingly, the fibers were also highly selective for mercury in comparison to $\mathrm{Cd}^{2+}, \mathrm{Co}^{2+}, \mathrm{Cu}^{2+}, \mathrm{Fe}^{3+}, \mathrm{Pb}^{2+}$, and $\mathrm{Zn}^{2+}$. This result bodes well for the removal of mercury from complex mixtures, which is a common scenario in remediation.

Han, Hong, Yoon, and co-workers have also reported the use of electrospinning to provide sulfur-rich materials for mercury sorption. ${ }^{61}$ In their strategy, non-woven fiber mats were first prepared by electrospinning a solution of poly(vinyl alcohol) $\left(M_{\mathrm{w}}=89,000\right.$ to $\left.98,000 \mathrm{~g} / \mathrm{mol}\right)$ and poly(acrylic acid) $\left(M_{\mathrm{w}} \sim 100,00 \mathrm{~g} / \mathrm{mol}\right)$. To integrate the sulfur polymer, the nanofiber mat was dip-coated in a solution of poly(S-r-DIB) (60 wt\% sulfur) in dichlorobenzene and then cured at $120{ }^{\circ} \mathrm{C}$ for 30 minutes. The sulfur polymer showed good adhesion to the fibers and mechanical robustness. The sulfur-rich nanofiber film showed effective mercury uptake capacity, with $26 \mathrm{mg}$ mercury bound per $g$ fiber. ${ }^{61}$

Kim, Chung, and associates have also taken advantage of electrospinning to make high surface-area polymers that are sulfur-rich. $^{62}$ Their sulfur polymers were prepared by reacting sulfur with hydrophilic alkene co-monomers such as methacrylic acid and 2-carboxyethyl acrylate. These sulfur polymers improved mercury uptake by virtue of their 
hydrophilicity, in comparison to hydrophobic sulfur polymers. ${ }^{62,63}$ These sulfur polymers were soluble in DMF and could be processed by electrospinning into micro- and nanofibrous mats when a polyacrylonitrile (PAN) carrier polymer was used, with the amount of PAN varying from 33 to $66 \%$ of the total polymer mixture. ${ }^{62}$ These mats exhibited exceptional mercury-binding capacities $\left(q_{\mathrm{m}}=634-835 \mathrm{mg}\right.$ $\mathrm{Hg} / \mathrm{g}$ sulfur polymer, depending on the composition) and the fibrous membranes could be used for removal of mercury from water via filtration. ${ }^{62}$ This study was also important in that it highlighted the importance of hydrophilicity of the sorbent for removing mercury from water and the additional mercury binding imparted from the organic crosslinker. ${ }^{62}$ Other insights included the regeneration of the sorbent with $6 \mathrm{M} \mathrm{HCl}$, which allowed recyclability.

As mentioned previously, coating pre-formed high surface-area materials is a useful strategy for increasing the effective surface area and available mercury-binding sites for the sulfur polymer. This was noted, for instance, in the dip-coating strategy for electrospun fibers reported by Yoon et al. ${ }^{61} \mathrm{~A}$ key criterion for coating strategies to work is for the sulfur polymer or pre-polymer to be processible (typically in solvents). Hasell and co-workers have taken advantage of the limonene polysulfide's solubility in a variety of organic solvents to coat silica gel. ${ }^{27}$ Simply dryloading the polymer onto silica provides a very effective mercury sorbent, even with only $10 \%$ of the mass of the sorbent coming from the polymer. ${ }^{27}$ Remarkably, $>700 \mathrm{mg}$ of $\mathrm{Hg}(\mathrm{II})$ could be bound per $\mathrm{g}$ polymer. A sample of the sorbent, which can be prepared in $\mathrm{kg}$ quantities, is shown in Figure 5.

Another innovative coating method was recently reported by Levkin, Theato and co-workers, in which a linear sulfur pre-polymer is made first and then coated on the desired substrate. ${ }^{30}$ Then, to cure the polymer, a trimethoxysilane group contained in the original organic monomer is crosslinked through a polycondensation reaction (Figure 6). The method is compatible with spin coating, dip coating, and solution casting. ${ }^{30}$ A variety of particles, fibers and surfaces could be coated with this method. An advantage of this strategy is the mild conditions required for curing, and the chemical resilience of the final product. Regarding mercury remediation, the authors demonstrated that they could coat silica particles, cure the polymer, and then rapidly remove $\mathrm{Hg}(\mathrm{II})$ from water. ${ }^{30}$

\section{Crosslinker Considerations}

While the polysulfides in polymers made by inverse vulcanization are clearly important for mercury binding, the structure and function of the organic crosslinker are also important. For example, Yagci, Kiskan and collaborators

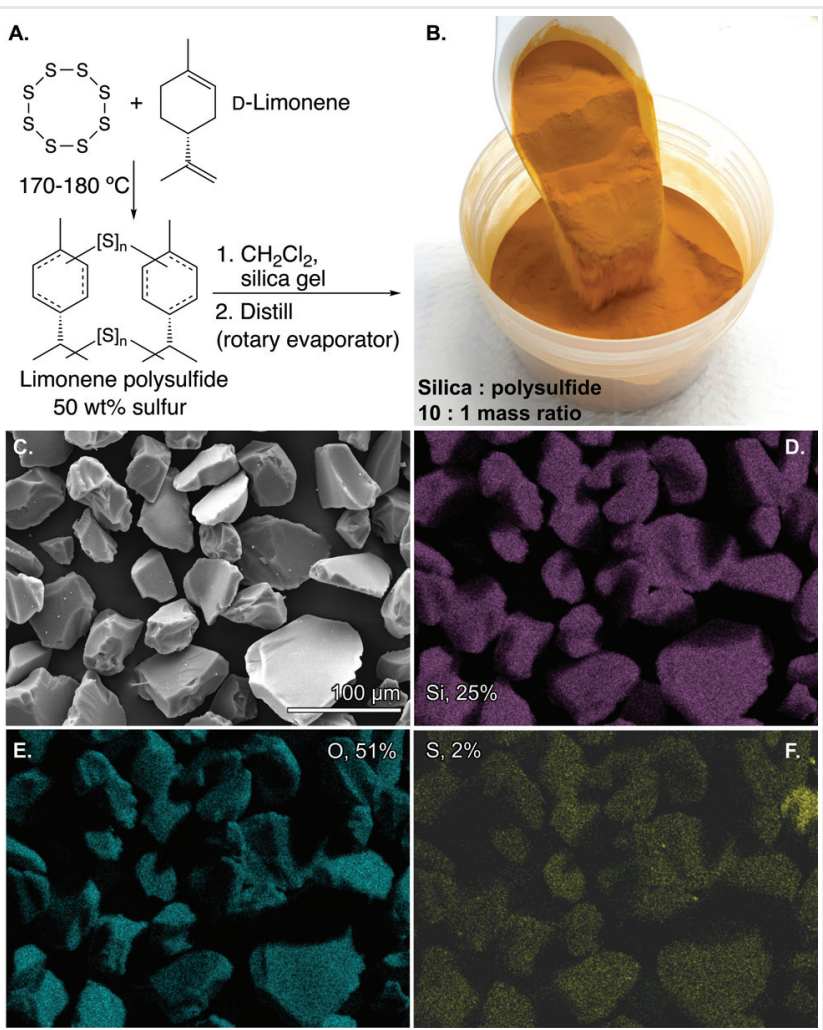

Figure 5 A) The direct reaction of sulfur and limonene produces oligomeric polysulfides that are soluble in organic solvents. B) Dry loading the polysulfide on silica gel produces a high surface area, free-flowing sorbent for rapid mercury sorption in water. This is a complementary architecture for the same polymer shown in Figure 2. The $300 \mathrm{~g}$ sample shown was prepared in the authors' lab based on previously published methods. ${ }^{9,27,54} \mathrm{C}$ ) SEM micrograph of the coated silica. D) EDX elemental mapping showing the silicon, E) oxygen, and F) sulfur on the sorbent surface. The patent associated with the limonene polysulfide polymer is assigned to Clean Earth Technologies.

have merged inverse vulcanization with co-formation of polybenzoxazines (Figure 7). ${ }^{64}$ The resulting polymer contains polysulfides, amines, and phenolic groups that can all potentially bind or even chelate mercury, as depicted in Figure 7. In this study, the authors also investigated the effects of $\mathrm{Hg}(\mathrm{II})$ concentration, sulfur content, $\mathrm{pH}$, and temperature on the performance of these sorbents. ${ }^{64}$

Another important effect of the organic crosslinker is its hydrophilicity. This property can influence wetting and the mass transport of mercury to the binding sites on the sorbent. Hasell and co-workers have noted this effect for polymers made from perillyl alcohol and sulfur (Figure 8). ${ }^{65}$ In the removal of $\mathrm{HgCl}_{2}$ from water, the perillyl copolymer was more effective than related hydrophobic polymers with similar sulfur content. However, this effect was not conferred to the removal of more hydrophobic mercury species such as methyl mercury, which indicates the speciation of the mercury is important to consider too. ${ }^{65}$ 
<smiles>C=Cc1cccc(CC[Si](OC)(OC)OC)c1</smiles><smiles>CO[Si](CCc1cccc(C(CC(C)(C)C)[Al]CC(C)(C)C)c1)(OC)OC</smiles>
$\mathrm{pH}=4, \mathrm{rt}$

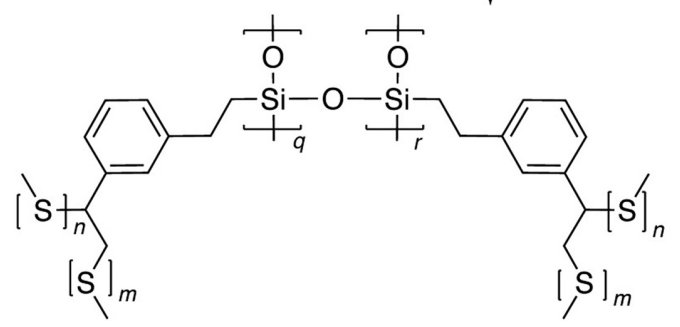

Figure 6 A solution processible pre-polymer can be formed by the reaction of sulfur with a trimethoxysilane-functionalized styrene derivative. The pre-polymer can be coated on a variety of substrates such as fibers, particles and surfaces. Condensation under mild conditions ( $\mathrm{pH}=4$, room temperature) crosslinks the polymer. Silica gel coated by this method was highly effective at mercury sorption. ${ }^{30}$

Kim, Chung, and associates have also recognized the importance of hydrophilicity of the sorbent in removing ionic mercury from water. In their copolymerizations of sulfur and hydrophilic monomers such as methacrylic acid and 2-carboxyethyl acrylate, significant hydrophilicity was imparted to the sorbent (Figure 8). ${ }^{62,63}$ The carboxylate functionality and polysulfide groups were both proposed to bind to mercury as well. These polymers could be integrated into nanofibers by electrospinning, as discussed previously. ${ }^{62}$ Alternatively, mercury sorbent beads could be fashioned by agar gelation. ${ }^{63}$ The base sulfur polymers were excellent in mercury sorption, with Langmuir sorption capacities approaching $1000 \mathrm{mg} \mathrm{Hg}^{2+} / \mathrm{g}$ in some cases. ${ }^{63}$

Tikoalu et al. also recently noted some subtle effects on the rate of mercury uptake and how it may depend on the hydrophilicity of the organic crosslinker (Figure 8). ${ }^{66}$ For example, castor oil contains a hydroxylated fatty acid ester that improved the initial rate of $\mathrm{Hg}$ (II) uptake in a copolymer made from the castor oil triglyceride and sulfur. For alkyl mercury compounds, the rate of uptake was not enhanced, likely due to the more lipophilic nature of that mercury species. ${ }^{66}$

Polar groups that increase hydrophilicity and/or chelation to mercury can also be introduced post-polymerization. For instance, Chen et al. showed that a polymer made from unsaturated triglycerides such as cottonseed oil and sulfur can be functionalized after inverse vulcanization (Figure 9). ${ }^{67}$ The post-polymer modification relies on the

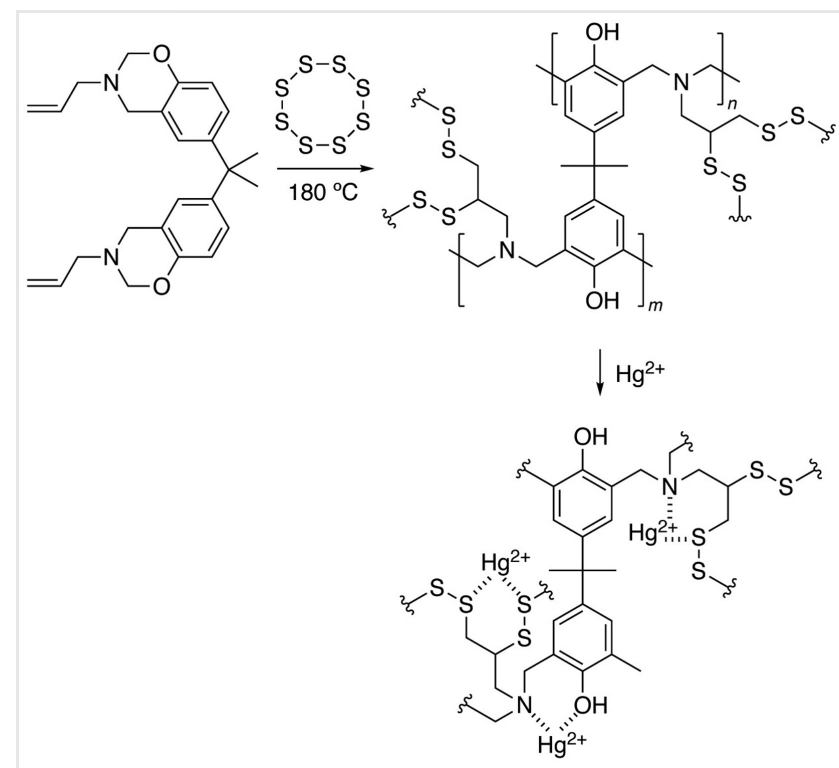

Figure 7 The organic component of polymers made by inverse vulcanization may also bind to mercury, as proposed by Kiskan, Yagci and co-workers for poly(benzoxazine-co-sulfur) polymers. ${ }^{64} \mathrm{~A}$ simplified structure of the polymer is shown, indicating benzoxazine polymerization and reaction of sulfur with the alkene of the $\mathrm{N}$-allyl amine. Potential chelating interactions of mercury(II) with the polysulfide, phenol and amine are depicted.

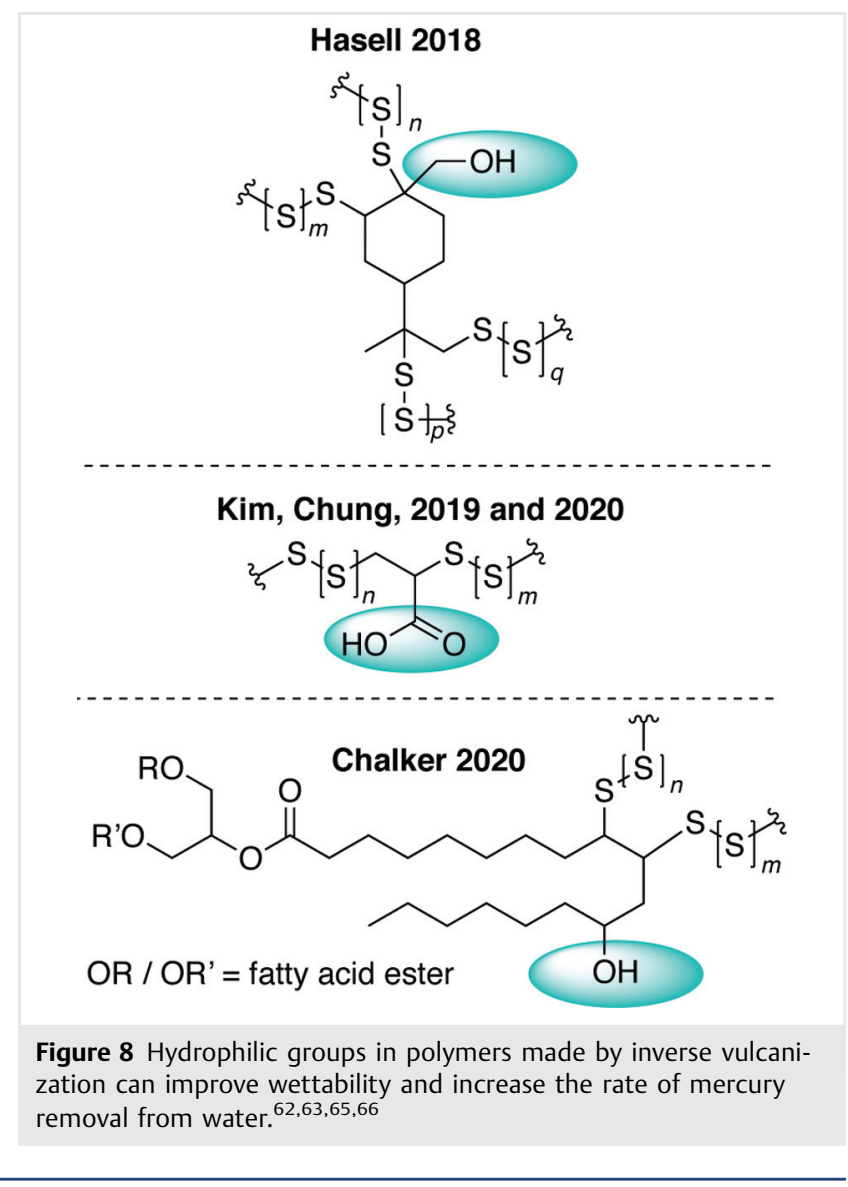


S-S bonds in the polysulfide, which can be homolytically cleaved with heating. The resulting thiyl radicals can then react with alkenes such as acrylate derivatives to install hydrophilic or chelating groups (Figure 9) ${ }^{67}$ Such insertion reactions had been previously described by Pyun ${ }^{68}$ and Jenkins, ${ }^{69}$ which take advantage of the dynamic S-S bonds in these polymers. For the modification shown in Figure 9, the Langmuir-Freundlich isotherm models indicated a maximum adsorption capacity of $343 \mathrm{mg} / \mathrm{g}$. Depending on the amount of amines incorporated into the polymer, the sorption capacity was increased up to 5-fold in comparison to the unmodified polymer (Figure 9 ).

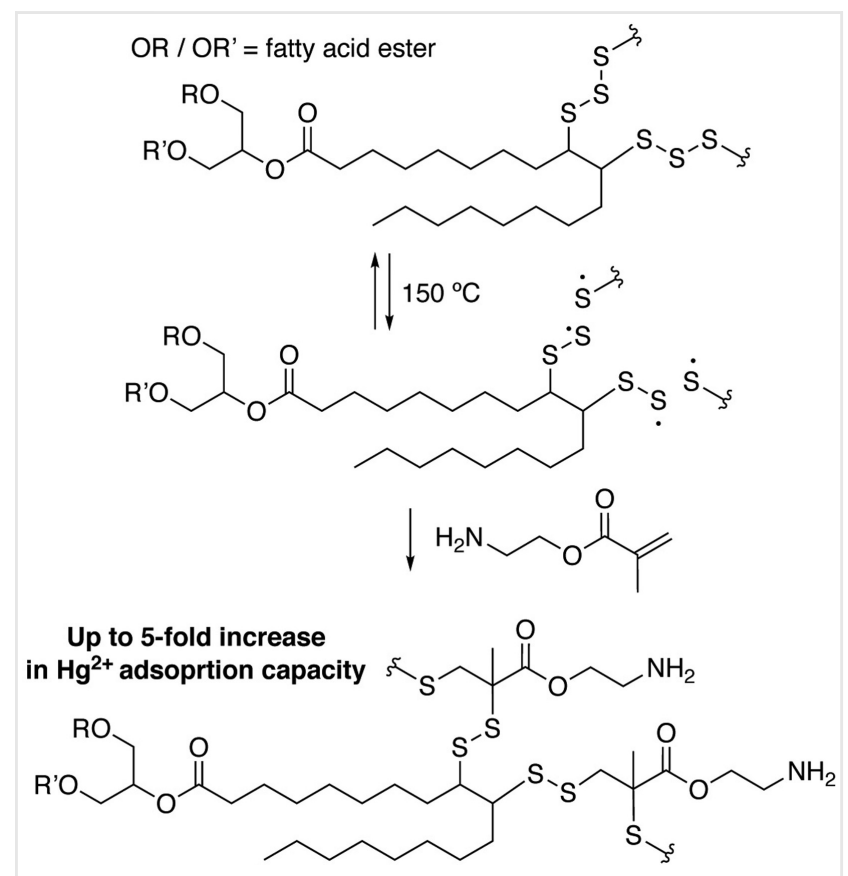

Figure 9 A polymer made from cottonseed oil and sulfur was modified post-polymerization. The additional amine functionality improved the mercury sorption capacity by as much as 5 -fold in comparison to the base polymer.

A motivating factor for using elemental sulfur as a monomer is its wide abundance and low cost, with 79 million tonnes produced in 2019 from petroleum refining and hundreds of billions of tonnes available geologically. ${ }^{13}$ In order for this sulfur to be deployed on large scale for inverse vulcanization, however, the abundance, cost, and sustainability of the organic component must also be considered. For this reason, there has been substantial interest in the copolymerization of sulfur with renewable organic crosslinkers to provide mercury sorbents. These crosslinkers include terpenes, ${ }^{9,12,27,65}$ unsaturated triglycerides, ${ }^{10,66,67,70}$ and other plant-based materials. ${ }^{71}$ This focus has led to studies on up-scaling to $\mathrm{kg}$ quantities of a polymer made from sulfur and canola oil (including used cooking oil) in a lab-based setting. ${ }^{40}$ This foundational work has since led to commercial production on the tonne-scale for this material using a proprietary process. This material is currently being deployed for commercial use in mercury remediation and other environmentally beneficial applications (Figure 10).

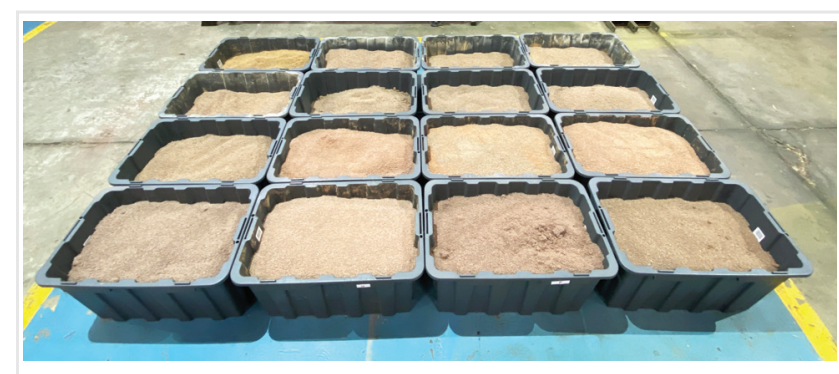

Figure 10 A mercury sorbent made from canola oil and sulfur can be manufactured on a multi-tonne scale. A $500 \mathrm{~kg}$ sample manufactured by Clean Earth Technologies is shown in the image. Reprinted with permission from Clean Earth Technologies.

\section{Sorption of Different Forms of Mercury}

For most of the mercury sorbents made by inverse vulcanization, their mercury sorption properties are most commonly evaluated in the removal of $\mathrm{HgCl}_{2}$ or $\mathrm{Hg}\left(\mathrm{NO}_{3}\right)_{2}$ from water. These are convenient models for characterizing binding to inorganic mercury, providing rigorous quantitative data on kinetics and sorption capacities. Additionally, these mercury species are safer to handle than other forms of mercury such as mercury gas or organomercury compounds. Yet, while removal of inorganic mercury from water is indeed important, many remediation activities encounter other forms of mercury, often in complex mixtures. For this reason, it is important to assess mercury sorbents against these other forms of mercury and in media that reflect field conditions.

For instance, water or soils contaminated with inorganic mercury can be challenging to remediate when the mercury is bound to organic materials such as humic substances. ${ }^{72}$ For polymers made by inverse vulcanization, an increased surface area was required to compete with humic matter in binding to inorganic mercury in water. ${ }^{10}$ Another important type of mercury sorption to test is binding to alkyl mercury compounds. These mercury species are highly toxic due to their ability to absorb through skin, cross-membranes, and accumulate in tissue. ${ }^{73}$ The lipophilic nature of these mercury species also influences how strongly they bind to sorbents. For instance, Hasell and co-workers have shown that methyl mercury has a higher affinity for hydrophobic sulfur polymers than hydrophilic sulfur polymers. ${ }^{65}$ Alkyl 
mercury fungicides were also shown by Worthington et al. ${ }^{10}$ and Tikoalu et al. ${ }^{66}$ to bind to hydrophobic sulfur polymers made from sulfur and triglycerides. In some cases the rates of sorption was different for the organomercury compounds compared to inorganic mercury, highlighting the need to assess multiple mercury species when evaluating a new sorbent. ${ }^{66}$ These observations also suggest not only that the hydrophilicity and hydrophobicity of the polymers are important for wetting (as discussed in the previous section), but also that the hydrophobicity and hydrophilicity of the mercury species should be considered so that it is matched to the appropriate sorbent for maximum affinity. For ionic inorganic mercury, hydrophilic sulfur polymers appear to perform better than hydrophobic sulfur polymers in the rate of mercury sorption. For lipophilic alkylmercury compounds, hydrophobic sulfur polymers perform better, with a higher affinity and capacity than more polar sulfur polymers. Ultimately, additional studies are required to clarify how the hydrophobicity and hydrophilicity of sulfur polymers influence the rate and capacity of binding to different mercury species.

Finally, one of the most common types of mercury encountered in remediation is elemental mercury, $\mathrm{Hg}(0)$. Elemental mercury vapor is produced in flue gas in cement production, coal combustion, and in industrial metallurgy. ${ }^{1,5}$ Liquid mercury is also used extensively in artisanal and small-scale gold mining (ASGM). ${ }^{2}$ Combined, coal combustion for power production and ASGM are responsible for the majority of mercury emissions on Earth. ${ }^{1}$ It is therefore important to evaluate mercury sorbents on elemental mercury. Accordingly, Worthington et al. evaluated the reaction of elemental mercury with a polymer made from sulfur and canola oil. ${ }^{10}$ It was found that the polysulfide oxidizes the elemental mercury to metacinnabar, which immobilizes the mercury and results in a color change (Figure 11). ${ }^{10}$ This process is more rapid than the related reaction with $\mathrm{S}_{8}$, indicating the more reactive nature of the polysulfide species in comparison to elemental sulfur. ${ }^{66}$ This reaction could be used to remove elemental mercury from soil by simply milling the polymer particles with mercury-contaminated soil and then sieving (Figure 11). ${ }^{10}$ Similar strategies of removing elemental mercury

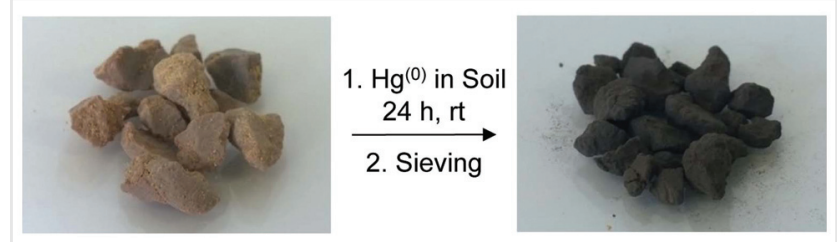

Figure 11 Mercury metal reacts with a polysulfide made from canola oil and sulfur. The production of metacinnabar renders the mercury non-volatile and therefore safer. A color change can also be observed in this process. Reprinted from Ref. 10 published under a creative commons license (CC BY). from water and soil were also reported soon after by Limjuco et al. using more hydrophilic sulfur polymers. ${ }^{63}$

Worthington and collaborators also showed that the same reaction happens with mercury gas, with the mercury delivered precisely in a nitrogen stream using a mass flow controller. ${ }^{10}$ In this case, mercury removal efficiency was highest at $75{ }^{\circ} \mathrm{C}$, indicating higher temperatures increase the rate of the reaction of the polymer with the mercury gas.

Alhassan and co-workers also studied the removal of elemental mercury from the gas phase using a polymer made from sulfur and divinyl benzene. ${ }^{48}$ In this study porosity was imparted to the polymer using a sodium chloride porogen. Alhassan et al. also observed an increase in mercury sorption capacity with temperature, with $151 \mathrm{mg}$ mercury bound per $\mathrm{g}$ of polymer sorbent at $60^{\circ}$ C. Conversion of mercury to $\mathrm{HgS}$ was also confirmed by XRD, indicating the polymer is a reactive sorbent and acts via a chemisorption process. The mercury absorption capacity of the polymer was shown to be far higher than elemental sulfur $(6 \mathrm{mg} / \mathrm{g})$ and on the same order of efficiency of several commercial carbons $(90-240 \mathrm{mg} / \mathrm{g}){ }^{48}$

\section{Life-Cycle Management}

The storage, transport, regeneration, and overall lifecycle management of mercury sorbents are an important consideration for industrial use. For polymers made by inverse vulcanization, there have been emerging reports of sorbent regeneration. For instance, Limjuco et al. have shown that quantitative regeneration of their electrospun sulfur polymers can be achieved by washing with $6 \mathrm{M} \mathrm{HCl}^{62}$ For their related microbeads made with the same sulfur polymers, Limjuco et al. found that a $0.5 \mathrm{M}$ solution of $\mathrm{HCl}$ containing $1.0 \mathrm{M}$ thiourea was effective at stripping the mercury off the sorbent. ${ }^{63}$ In related studies, Chen et al. found that a nitric acid wash was suitable for regenerating sulfur polymer sorbents with bound $\mathrm{Hg}(\mathrm{II}) .{ }^{67}$ These capabilities are important for the recyclability of sulfur polymer sorbents, particularly those used in filtration applications. This also highlights the general acid stability of polymers made by inverse vulcanization. ${ }^{42,74}$ With that said, the stripping solution would still have to be processed as waste to separate the mercury from the water. Furthermore, if acid can remove mercury from these polymers, then they might not be suitable for mercury remediation at low $\mathrm{pH}$.

An alternative approach is the long-term stabilization and storage of the mercury bound to the sorbent. ${ }^{75-78}$ This is of particular relevance to elemental mercury, which is often the final product obtained in mercury recovery units in industry operations and waste management facilities. As restrictions on the use and trade of elemental mercury increase, there will be a need for a long-term strategy for 
mercury storage and management. Reacting mercury with elemental sulfur and trapping it in a solid sulfur polymer or composite lowers the vapor pressure of the mercury by converting it into a mercury sulfide. ${ }^{75}$ As mercury vapor is extremely hazardous, converting elemental mercury to a non-volatile species is important for long-term storage. The mercury sulfide product, stabilized in monolithic blocks of sulfur, is also resistant to water and freeze-thaw processes that would otherwise result in leaching. ${ }^{76,78}$ This immobilization and low-leaching renders the mercury product essentially non-hazardous. ${ }^{78}$ Polymers made by inverse vulcanization have potential for similar processing and long-term storage, particularly for remediation of elemental mercury. These polymers react faster than elemental sulfur with mercury, ${ }^{48,66}$ and result in the same stable HgS product, which is highly insoluble with negligible vapor pressure. An additional feature of some polymers made by inverse vulcanization is that they can be hot-pressed at relatively low temperatures $\left(\sim 100{ }^{\circ} \mathrm{C}\right)$ and undergo $\mathrm{S}-\mathrm{S}$ metathesis at the polymer interfaces to provide solid blocks and composites. ${ }^{43}$ Lundquist et al. have recently shown that this reactive compression molding can be used to lock in heavy metals into the polymer and prevent leaching. ${ }^{79}$ Such processing might be complementary or used in conjunction with the sulfur solidification and stabilization process.

\section{Conclusions and Outlook}

The synthesis of polymers by inverse vulcanization has provided a variety of materials that are effective as mercury sorbents. The sulfur from the polysulfide groups in the polymer is critical for binding and in some cases reacting with mercury, but the organic crosslinker is also important in tailoring the physical properties and mercury affinity. The diverse physical forms of polymers made by inverse vulcanization have also enabled a variety of architectures useful for deployment in mercury remediation. High surface-area fibers, foams, beads, powders and other forms of these high-sulfur materials have proven useful in mercury capture. In future studies, it will be necessary to more thoroughly evaluate these sorbents in field conditions to assess their true potential in mercury remediation. In this way, we will be able to understand how the rate and capacity of mercury uptake is influenced not just by the polymer structure, but also by the $\mathrm{pH}$, ionic strength, organic matter, flow rate, and temperature of contaminated waterways. Similar studies will also be required for gas streams contaminated by mercury to test if these sulfur polymers can capture mercury in the presence of other gases that could foul the sorbent. Similarly, as progress continues on the manufacture and life-cycle management of these materials, we anticipate increased industrial use of these polymers in the management of mercury emissions and pollution.

\section{Funding Information}

Funding for the authors' research is provided by the Australian Research Council (DP200100090) and Clean Earth Technologies.

\section{Acknowledgment}

The authors acknowledge additional financial and research facility support from Flinders University. The authors acknowledge Clean Earth Technologies and Adelaide Control Engineering for collaboration in the up-scaling and commercial production of sulfur-rich materials for mercury remediation.

\section{Conflict of Interest}

J.M.C., M.M., and M.J.H.W. are inventors on patents assigned to Clean Earth Technologies. These patents include mercury sorbents discussed in this review. L.J.E. is an employee of Clean Earth Technologies, which manufactures the mercury sorbents described in Figure 5 and Figure 10.

\section{References}

(1) Global Mercury Assessment 2018, UN Environment Programme, Chemicals and Health Branch. Geneva, Switzerland, 2019.

(2) Esdaile, L. J.; Chalker, J. M. Chem. Eur. J. 2018, 24, 6905.

(3) Obrist, D.; Kirk, J. L.; Zhang, L.; Sunderland, E. M.; Jiskra, M.; Selin, N. E. AMBIO 2018, 47, 116.

(4) Kunecki, P.; Czarna-Juszkiewicz, D.; Wdowin, M. Int. J. Coal Sci. Technol. 2021, 8, 23.

(5) Wang, L.; Hou, D.; Cao, Y.; Ok, Y. S.; Tack, F. M. G.; Rinklebe, J.; O'Connor, D. Environ. Int. 2020, 134, 105281.

(6) Coulibaly, M.; Bamba, D.; Yao, N. G. A.; Zoro, E. G.; Rhaz, M. E. C.R. Chim. 2016, 19, 832.

(7) Liu, D.; Li, C.; Wu, J.; Liu, Y. Chem. Eng. J. 2020, 391, 123514.

(8) Yu, J.-G.; Yue, B.-Y.; Wu, X.-W.; Liu, Q.; Jiao, F.-P.; Jiang, X.-Y.; Chen, X.-Q. Eviron. Sci. Pollut. Res. 2016, 23, 5056.

(9) Crockett, M. P.; Evans, A. M.; Worthington, M.J.H.; Albuquerque, I. S.; Slattery, A. D.; Gibson, C. T.; Campbell,J. A.; Lewis, D. A.; Bernardes, G. J. L.; Chalker, J. M. Angew. Chem. Int. Ed. 2016, 55, 1714.

(10) Worthington, M. J. H.; Kucera, R. L.; Albuquerque, I. S.; Gibson, C. T.; Sibley, A.; Slattery, A. D.; Campbell, J. A.; Alboaiji, S. F. K.; Muller, K. A.; Young, J.; Adamson, N.; Gascooke, J. R.; Jampaiah, D.; Sabri, Y. M.; Bhargava, S. K.; Ippolito, S. J.; Lewis, D. A.; Quinton, J. S.; Ellis, A. V.; Johs, A.; Bernardes, G. J. L.; Chalker, J. M. Chem. Eur. J. 2017, 23, 16219.

(11) Hasell, T.; Parker, D. J.; Jones, H. A.; McAllister, T.; Howdle, S. M. Chem. Commun. 2016, 52, 5383. 
(12) Parker, D. J.; Jones, H. A.; Petcher, S.; Cervini, L.; Griffin, J. M.; Akhtar, R.; Hasell, T. J. Mater. Chem. A 2017, 5, 11682.

(13) Apodaca, L. E. Sulfur: Mineral Commodity Summaries, January 2020. Reston, Virginia: U.S. Geological Survey.

(14) Chung, W. J.; Griebel, J. J.; Kim, E. T.; Yoon, H.; Simmonds, A. G.; Ji, H. J.; Dirlam, P. T.; Glass, R. S.; Wie, J. J.; Nguyen, N. A.; Guralnick, B. W.; Park, J.; Somogyi, A.; Theato, P.; Mackay, M. E.; Sung, Y.-E.; Char, K.; Pyun, J. Nat. Chem. 2013, 5, 518.

(15) Tian, T.; Hu, R.; Tang, B. Z. J. Am. Chem. Soc. 2018, 140, 6156.

(16) Yasin, A.; Chen, Y.; Liu, Y.; Zhang, L.; Zan, X.; Zhang, Y. Polym. Chem. 2020, 11, 810.

(17) Meyer, B. Chem. Rev. 1976, 76, 367.

(18) Currell, B. R.; Williams, A. J.; Mooney, A. J.; Nash, B. J. Plasticization of Sulfur. In: New Uses of Sulfur. West, J. American Chemical Society: Washington, DC, 1975, Vol. 140, 1-17.

(19) McBee, W. C.; Sullivan, T. A.; Fike, H. L. Sulfur Construction Materials. United States Department of the Interior, Bureau of Mines; 1985, Bulletin 678; 1-31.

(20) Griebel, J. J.; Glass, R. S.; Char, K.; Pyun, J. Prog. Polym. Sci. 2016, $58,90$.

(21) Zhang, Y.; Glass, R. S.; Char, K.; Pyun, J. Polym. Chem. 2019, 10, 4078.

(22) Worthington, M. J. H.; Kucera, R. L.; Chalker, J. M. Green Chem. 2017, 19, 2748.

(23) Chalker, J. M.; Worthington, M. J. H.; Lundquist, N. A.; Esdaile, L. J. Top. Curr. Chem. 2019, 377, 16.

(24) Zhang, Y.; Griebel, J. J.; Dirlam, P. T.; Nguyen, N. A.; Glass, R. S.; Mackay, M. E.; Char, K.; Pyun, J.J. Polym. Sci., Part A: Polym. Chem. 2017, 55, 107.

(25) Park, S.; Lee, D.; Cho, H.; Lim, J.; Char, K. ACS Macro Lett. 2019, 8, 1670.

(26) Orme, K.; Fistrovich, A. H.; Jenkins, C. L. Macromolecules 2020, 53, 9353.

(27) Wu, X.; Smith, J. A.; Petcher, S.; Zhang, B.; Parker, D. J.; Griffin, J. M.; Hasell, T. Nat. Commun. 2019, 10, 647.

(28) Shankarayya Wadi, V. K.; Jena, K. K.; Khawaja, S. Z.; Yannakopoulou, K.; Fardis, M.; Mitrikas, G.; Karagianni, M.; Papavassiliou, G.; Alhassan, S. M. ACS Omega 2018, 3, 3330.

(29) Tonkin, S. J.; Gibson, C. T.; Campbell, J. A.; Lewis, D. A.; Karton, A.; Hasell, T.; Chalker, J. M. Chem. Sci. 2020, 11, 5537.

(30) Scheiger, J. M.; Direksilp, C.; Falkenstein, P.; Welle, A.; Koenig, M.; Heissler, S.; Matysik, J.; Levkin, P. A.; Theato, P. Angew. Chem. Int. Ed. 2020, 59, 18639.

(31) Zhang, Y.; Pavlopoulos, N. G.; Kleine, T. S.; Karayilan, M.; Glass, R. S.; Char, K.; Pyun, J.J. Polym. Sci. Part A: Polym. Chem. 2019, $57,7$.

(32) Smith, J. A.; Green, S. J.; Petcher, S.; Parker, D. J.; Zhang, B.; Worthington, M. J. H.; Wu, X.; Kelly, C. A.; Baker, T.; Gibson, C. T.; Campbell, J. A.; Lewis, D. A.; Jenkins, M. J.; Willcock, H.; Chalker, J. M.; Hasell, T. Chem. Eur. J. 2019, 25, 10433.

(33) Kleine, T. S.; Nguyen, N. A.; Anderson, L. E.; Namnabat, S.; LaVilla, E. A.; Showghi, S. A.; Dirlam, P. T.; Arrington, C. B.; Manchester, M. S.; Schwiegerling, J.; Glass, R. S.; Char, K.; Norwood, R. A.; Mackay, M. E.; Pyun, J. ACS Macro Lett. 2016, 5, 1152.

(34) Griebel, J. J.; Namnabat, S.; Kim, E. T.; Himmelhuber, R.; Moronta, D. H.; Chung, W. J.; Simmonds, A. G.; Kim, K.-J.; van der Laan, J.; Nguyen, N. A.; Dereniak, E. L.; Mackay, M. E.; Char, K.; Glass, R. S.; Norwood, R. A.; Pyun, J. Adv. Mater. 2014, 26, 3014.

(35) Boyd, D. A.; Nguyen, V. Q.; McClain, C. C.; Kung, F. H.; Baker, C. C.; Myers, J. D.; Hunt, M. P.; Kim, W.; Sanghera, J. S. ACS Macro Lett. 2019, 8, 113.

(36) Kleine, T. S.; Glass, R. S.; Lichtenberger, D. L.; Mackay, M. E.; Char, K.; Norwood, R. A.; Pyun, J. ACS Macro Lett. 2020, 9, 245.
(37) Griebel, J. J.; Nguyen, N. A.; Namnabat, S.; Anderson, L. E.; Glass, R. S.; Norwood, R. A.; MacKay, M. E.; Char, K.; Pyun, J. ACS Macro Lett. 2015, 4, 862.

(38) Xin, Y.; Peng, H.; Xu, J.; Zhang, J. Adv. Funct. Mater. 2019, 29, 1808989.

(39) Lundquist, N. A.; Worthington, M.J. H.; Adamson, N.; Gibson, C. T.; Johnston, M. R.; Ellis, A. V.; Chalker, J. M. RSC Adv. 2018, 8, 1232.

(40) Worthington, M. J. H.; Shearer, C. J.; Esdaile, L. J.; Campbell, J. A.; Gibson, C. T.; Legg, S. K.; Yin, Y.; Lundquist, N. A.; Gascooke, J. R.; Albuquerque, I. S.; Shapter, J. G.; Andersson, G. G.; Lewis, D. A.; Bernardes, G. J. L.; Chalker, J. M. Adv. Sustainable Syst. 2018, 1800024.

(41) Karunarathna, M. S.; Lauer, M. K.; Thiounn, T.; Smith, R. C.; Tennyson, A. G. J. Mater. Chem. A 2019, 7, 15683.

(42) Lopez, C. V.; Karunarathna, M. S.; Lauer, M. K.; Maladeniya, C. P.; Thiounn, T.; Ackley, E. D.; Smith, R. C. J. Polym. Sci. 2020, 58, 2259.

(43) Lundquist, N. A.; Tikoalu, A. D.; Worthington, M. J. H.; Shapter, R.; Tonkin, S. J.; Stojcevski, F.; Mann, M.; Gibson, C. T.; Gascooke, J. R.; Karton, A.; Henderson, L. C.; Esdaile, L. J.; Chalker, J. M. Chem. Eur. J. 2020, 26, 10035.

(44) Bu Najmah, I.; Lundquist, N. A.; Stanfield, M. K.; Stojcevski, F.; Campbell, J. A.; Esdaile, L. J.; Gibson, C. T.; Lewis, D. A.; Henderson, L. C.; Hasell, T.; Chalker, J. M. ChemSusChem 2021, 14, 2353.

(45) Mann, M.; Kruger, J. E.; Andari, F.; McErlean, J.; Gascooke, J. R.; Smith, J. A.; Worthington, M. J. H.; McKinley, C. C. C.; Campbell, J. A.; Lewis, D. A.; Hasell, T.; Perkins, M. V.; Chalker, J. M. Org. Biomol. Chem. 2019, 17, 1929.

(46) Fortuna do Valle, S.; Giroto, A. S.; Reis, H. P. G.; Guimarães, G. G. F.; Ribeiro, C. J. Agric. Food. Chem. 2021, 69, 2392.

(47) Herrera, C.; Ysinga, K. J.; Jenkins, C. L. ACS Appl. Mater. Interfaces 2019, 11, 35312.

(48) Abraham, A. M.; Kumar, S. V.; Alhassan, S. M. Chem. Eng. J. 2018, 332, 1.

(49) Wadi, V. S.; Jena, K. K.; Khawaja, S. Z.; Ranagraj, V. M.; Alhassan, S. M. RSC Adv. 2019, 9, 4397.

(50) Yan, P.; Zhao, W.; Zhang, B.; Jiang, L.; Petcher, S.; Smith, J. A.; Parker, D. J.; Cooper, A. I.; Lei, J.; Hasell, T. Angew. Chem. Int. Ed. 2020, 59, 13371.

(51) Lee, J.-S. M.; Parker, D. J.; Cooper, A. I.; Hasell, T. J. Mater. Chem. A 2017, 5, 18603.

(52) Deng, Z.; Hoefling, A.; Theato, P.; Lienkamp, K. Macromol. Chem. Phys. 2018, 219, 1700497.

(53) Smith, J. A.; Mulhall, R.; Goodman, S.; Fleming, G.; Allison, H.; Raval, R.; Hasell, T. ACS Omega 2020, 5, 5229.

(54) Crockett, M. P.; Evans, A. M.; Worthington, M. J. H.; Chalker, J. M. Sulfur-Limonene Polysulfide. US Patent 10,590,012, 2020. Priority date 13 Oct 2015.

(55) Lin, H.-K.; Lai, Y.-S.; Liu, Y.-L. ACS Sustainable Chem. Eng. 2019, 7, 4515.

(56) Petcher, S.; Parker, D. J.; Hasell, T. Environ. Sci. Water Res. Technol. 2019, 5, 2142.

(57) Wadi, V. S.; Mittal, H.; Fosso-Kankeu, E.; Jena, K. K.; Alhassan, S. M. Colloids Surf., A 2020, 606, 125333.

(58) Xue, J.; Wu, T.; Dai, Y.; Xia, Y. Chem. Rev. 2019, 119, 5298.

(59) Greiner, A.; Wendorff, J. H. Angew. Chem. Int. Ed. 2007, 46, 5670.

(60) Thielke, M. W.; Bultema, L. A.; Brauer, D. D.; Richter, B.; Fischer, M.; Theato, P. Polymers 2016, 8, 266.

(61) Lee, J.; Lee, S.; Kim, J.; Hanif, Z.; Han, S.; Hong, S.; Yoon, M.-H. Bull. Korean Chem. Soc. 2018, 39, 84. 
(62) Limjuco, L. A.; Nisola, G. M.; Parohinog, K. J.; Valdehuesa, K. N. G.; Lee, S.-P.; Kim, H.; Chung, W.-J. Chem. Eng. J. 2019, 378, 122216.

(63) Limjuco, L. A.; Fissaha, H. T.; Kim, H.; Nisola, G. M.; Chung, W.-J. ACS Appl. Polym. Mater. 2020, 2, 4677.

(64) Akay, S.; Kayan, B.; Kalderis, D.; Arslan, M.; Yagci, Y.; Kiskan, B. J. Appl. Polym. Sci. 2017, 134, 45306.

(65) Parker, D. J.; Chong, S. T.; Hasell, T. RSC Adv. 2018, 8, 27892.

(66) Tikoalu, A. D.; Lundquist, N. A.; Chalker, J. M. Adv. Sustainable Syst. 2020, 4, 1900111

(67) Chen, Y.; Yasin, A.; Zhang, Y.; Zan, X.; Liu, Y.; Zhang, L. Materials 2020, 13, 632

(68) Zhang, Y.; Konopka, K. M.; Glass, R. S.; Char, K.; Pyun, J. Polym. Chem. 2017, 8, 5167.

(69) Westerman, C. R.; Jenkins, C. L. Macromolecules 2018, 51, 7233.

(70) Rollinson, A. N.; Bhuptani, J.; Beyer, J.; Ismawati, Y.; Radu, T. Int. J. Phytoremediation 2020, 22, 1431.
(71) Fu, Y.; Yang, C.; Zheng, Y.; Jiang, J.; Sun, Y.; Chen, F.; Hu, J. J. Mol. Liq. 2021, 328, 115420.

(72) Wang, Q.; Kim, D.; Dionysiou, D. D.; Sorial, G. A.; Timberlake, D. Environ. Pollut. 2004, 131, 323.

(73) Tchounwou, P. B.; Ayensu, W. K.; Ninashvili, N.; Sutton, D. Environ. Toxicol. 2003, 18, 149.

(74) Thiounn, T.; Tennyson, A. G.; Smith, R. C. RSC Adv. 2019, 9, 31460.

(75) Fuhrmann, M.; Melamed, D.; Kalb, P. D.; Adams, J. W.; Milian, L. W. Waste Manage. 2002, 22, 327.

(76) López-Delgado, A.; Guerrero, A.; López, F. A.; Perez, C.; Alguacil, F. J. Rev. Metal. 2012, 48, 58.

(77) Rodríguez, O.; Padilla, I.; Tayibi, H.; López-Delgado, A. J. Environ. Manage. 2012, 101, 197.

(78) López, F. A.; Alguacil, F. J.; Rodríguez, O.; Sierra, M. J.; Millán, R. Waste Manage. 2015, 35, 301.

(79) Lundquist, N. A.; Chalker, J. M. Sustainable Mater. Technol. 2020, 26, e00222. 